\title{
The Role of Chemotherapy in the Treatment of Malignant Astrocytomas
}

\author{
David Mathieu, David Fortin
}

\begin{abstract}
Malignant astrocytomas are aggressive neoplasms with a dismal prognosis despite optimal treatment. Maximal resective surgery is traditionally complemented by radiation therapy. Chemotherapy is now used on patients as initial therapy when their functional status is congruent with further treatment. The classic agents used are nitrosoureas, but temozolomide has taken the front seat recently, with recent data demonstrating increased survival when this agent is used concurrently with radiation therapy in newly diagnosed glioblastoma patients. A new class of agents, refered to as biological modifiers, are increasingly used in clinical trials in an effort to affect the intrinsic biologic aberrations harboured by tumor cells. These drugs comprise differentiation agents, anti-angiogenic agents, matrix-metalloproteinase inhibitors and signal transduction inhibitors, among others. This article reviews the standard cytotoxic agents that have been used to treat malignant astrocytomas, and the different combination regimens offering promise. In addition, recent advances with biological modifiers are also discussed.
\end{abstract}

\begin{abstract}
RÉSUMÉ: Rôle de la chimiothérapie dans le traitement de l'astrocytome malin. Les astrocytomes malins sont des tumeurs agressives dont le pronostic est sombre en dépit d'un traitement optimal. Traditionnellement, la radiothérapie servait de complément à la résection maximale. La chimiothérapie est maintenant utilisée initialement, si l'état du patient le justifie. Les agents classiques utilisés sont les nitrosourées. Cependant, le temozolomide les a supplantées récemment parce qu'on a observé une prolongation de la survie quand cet agent est utilisé en même temps que la radiothérapie chez les nouveaux patients. Une nouvelle classe d'agents, des modificateurs de la réponse biologique, font l'objet d'essais thérapeutiques de plus en plus nombreux pour tenter de contrecarrer les aberrations biologiques intrinsèques des cellules tumorales. Parmi ces substances, notons des agents de différenciation, des agents antiangiogéniques, des inhibiteurs des métalloprotéinases matricielles et des inhibiteurs de la transduction du signal. Cet article revoit les agents cytotoxiques standards utilisés dans le traitement des astrocytomes malins et les différentes combinaisons thérapeutiques prometteuses ainsi que les progrès récents réalisés dans l'étude des modificateurs de la réponse biologique.
\end{abstract}

Can. J. Neurol. Sci. 2006; 33: 127-140

Three major histological types of diffuse infiltrative tumors are recognized by the World Health Organization's classification of gliomas: astrocytoma, oligodendrogliomas, and oligoastrocytomas. ${ }^{1}$ These tumors are further classified by subtypes (mainly for astrocytomas) and by histological grading. Grading usually serves the purpose of orienting treatment and predicting in the most accurate way the outcome for a given patient. Glial neoplasms represent a continuum of increasingly cellular and pleiomorphic lesions. ${ }^{1-3}$ Therefore grading systems translate a punctual assessment of this continuum, and can only approximate the biological behavior of a tumor. For astrocytic tumors, a four tier system is used. ${ }^{3,4}$ The term malignant astrocytoma typically refers to grade III and IV fibrillary astrocytomas, respectively dubbed anaplastic astrocytoma (AA) and glioblastoma multiforme (GBM).
Malignant astrocytomas constitute about $50 \%$ to $60 \%$ of primary brain tumors, with an incidence ranging from 5 to 8 per 100000 inhabitants. ${ }^{5}$ Peak incidence is in the fifth or sixth decade of life, and has been increasing in recent years, an observation that may not be fully explained by aging of the population. ${ }^{6}$ In adults, malignant astrocytomas are almost

From the Divisions of Neurosurgery/Neuro-Oncology, Department of Surgery, Sherbrooke University and Centre Hospitalier Universitaire de Sherbrooke, Sherbrooke, Quebec, Canada.

ReCEIVED APRIL 12, 2005. ACCEPTED IN FINAL FORM JANUARY 30, 2006. Reprint requests to: David Fortin, Centre Hospitalier Universitaire de Sherbrooke (CHUS), 3001 - 12e Avenue Nord, Sherbrooke, Québec, J1H 5N4, Canada. 
exclusively supratentorial in location (over 90\%). These tumors spread by diffusely infiltrating the brain, and tumor cells are found at a distance from the enhancing anomalies on radiological studies. ${ }^{7}$ This fact accounts in part for their dismal prognosis, by preventing a complete resection and rendering local treatment modalities only partially effective.

Standard treatment for astrocytic tumors has traditionally consisted of maximal surgical resection, followed by radiotherapy. The most frequently used radiation dose-schedule consists of 60 Gy given in 30 fractions over six weeks. Even with this so-called optimal treatment, a cure cannot be considered an accessible goal. The median survival produced by this approach is only 35 to 48 weeks for patients bearing a GBM. ${ }^{8,9}$ Anaplastic astrocytoma patients fare better, with a median survival of two to three years, but eventually progress histologically to GBM. Hyperfractionation radiation protocols have not resulted in better responses or survival rates ${ }^{10,11}$ and neither has the tentative use of various radio-sensitizers within the schedule of treatment. ${ }^{12}$

The addition of standard cytotoxic chemotherapy offers a minimal survival advantage, raising the median survival to 51 weeks for GBM. ${ }^{13}$ Chemotherapeutic drug trials have been conducted worldwide for more than 4 decades, and most investigators agree that, until lately, little progress had been made since the introduction of the nitrosoureas. Temozolomide, a new agent introduced recently has been proven effective against malignant astrocytic tumors, and has contributed in improving the quality of life of the patients. ${ }^{14,15}$ Recent data even suggest that using this agent concurrently with radiation therapy after primary diagnosis significantly improves patients survival, as will be discussed later. ${ }^{16}$ However, a cure still remains an elusive goal.

Many issues regarding chemotherapy for malignant astrocytomas remain unsettled to this day. The optimal agent or combination of agent has yet to be identified. Investigators are still trying to combine standard cytotoxic agents in hope of finding an adequate regimen. The issue of delivery is still under investigation. The blood-brain barrier $(\mathrm{BBB})$ remains a major obstacle to the efficient treatment of these lesions and many strategies are being investigated to circumvent it. ${ }^{17}$ Appropriate timing of administration of the agents, whether in an adjuvant setting or at recurrence, is another area of uncertainty. All these topics will be further discussed in this paper.

\section{STANDARD Cytotoxic Therapy}

\section{Agent classes}

\section{Nitrosoureas}

Nitrosoureas are the most frequently used and the most studied agents in the treatment of malignant astrocytomas. They produce their cytotoxic effect by methylation of DNA mainly at the O6 position of guanine, a mechanism of action shared by all the alkylating agents. The interest in these agents comes from their important liposolubility, which enables them to effectively cross the blood-brain barrier to interact with the tumor cells. Nitrosoureas toxicity consists mostly in myelosupression, gastro-intestinal effects, cumulative nephrotoxicity and pulmonary fibrosis. This class of agent is also highly leukemogenic after prolonged courses. Carmustine (BCNU), which is administered parenterally and lomustine (CCNU), an oral derivative, are the two main drugs in this class. Nimustine (ACNU) is a newer agent.

These drugs have been studied in a variety of settings. The Brain Tumor Cooperative Group designed a number of protocols using BCNU in an adjuvant setting, immediately following surgery and radiation therapy. ${ }^{18,19}$ Globally, these studies demonstrated an increase in 18 and 24-months survival of $10 \%$ for patients who received the drug, even though each trial individually failed to demonstrate a significant benefit. ${ }^{20}$ In 1992, Fine and $\mathrm{al}^{21}$ conducted a meta-analysis designed to resolve the controversy on adjuvant chemotherapy. Most studies included in this analysis were nitrosourea-based. A slight survival benefit was found for patients who were given chemotherapy, their median survival being 12 months compared to 9.4 months for the patients not exposed. This translated into a $10.1 \%$ and $8.6 \%$ increase in 12 and 24-months survival, respectively. However, after subgroup analysis, this advantage was still present only for young patients (under 50 years of age) with anaplastic astrocytomas. Stewart ${ }^{22}$ conducted a similar analysis on 12 randomised studies, comparing radiotherapy alone with radiotherapy plus chemotherapy. Chemotherapy was also mostly nitrosoureas-based in the studies reviewed in this meta-analysis. The results showed a modest but clear advantage for the use of chemotherapy, with a $15 \%$ relative decrease in the risk of death, translating in a two months increase in median survival. In this analysis, no difference in the effect of chemotherapy was identified in any subgroup of patients as defined by age, sex, histology, performance status, or extent of resection. $^{22}$

Some investigators also explored the use of nitrosoureas in neoadjuvant setting, immediately after surgery. To date, this practice has not demonstrated a superior efficacy to commonly used regimen. However, as was found by Fine et al, ${ }^{21}$ delaying radiation therapy for up to eight weeks does not result in a decreased survival for the patients. Since radiation therapy can be associated with significant neurocognitive deficits for longterm survivors, ${ }^{23}$ studies using chemotherapy in a neoadjuvant setting could concordantly be proposed by investigators pursuing the goal of postponing radiotherapy.

Nitrosoureas, like the majority of chemotherapeutic agents, have mostly been used at tumor recurrence. In 1998, Huncharek and Muscat $^{8}$ published a systematic review of chemotherapy for recurrent malignant astrocytomas. Of the studies selected, 14 involved a form of nitrosoureas. The mean time to progression was 26.9 weeks, and mean survival was 32.1 weeks. Efficacy was better for patients who had not been previously exposed to cytotoxic drugs.

This data was recently confirmed by Brandes et al, ${ }^{24}$ who conducted a phase II study using carmustine on GBM patients at recurrence, after failed radiation therapy. The median time to progression (MTP) and median survival time (MST) were 13.3 weeks and 7.5 months respectively, which compares favorably with other trials. However, treatment was limited by significant toxicity.

\section{$P C V$}

Combination regimens were designed to increase the efficacy of the nitrosoureas. The most notable of these is the PCV regimen, consisting of procarbazine, $\mathrm{CCNU}$ and vincristine, 
which was designed by Levin et al. ${ }^{25}$ In 1990, this group published a phase III study comparing PCV against BCNU, followed by radiotherapy and hydroxyurea. Sixty-six patients were enrolled in the BCNU arm, and 67 in the PCV arm. There was no difference among GBM patients, but for anaplastic gliomas, PCV was superior in term of progression-free survival (125.6 vs. 62.7 weeks) and overall survival (157.1 vs. 82.1 weeks). These results led to the widespread use of PCV for glioma patients, despite the increased toxicity produced by this combination. However, the methodology of the study contained numerous flaws that soften the conclusions. Investigators had to re-analyze the data after excluding patients with Karnofsky score under 70 (which were included in the original eligibility criteria), after the first analysis showed no difference between the two groups. Moreover, the anaplastic glioma group comprised patients with a heterogeneous mixture of tumor histology, including astrocytomas, oligodendrogliomas and oligoastrocytomas. It is now well accepted that tumors displaying an oligodendroglial component are relatively chemosensitive compared to pure fibrillary astrocytomas, and that these different histologies should be analyzed separately in clinical trials. ${ }^{26}$

A recent paper, by Prados et al, ${ }^{27}$ retrospectively reviewed four of the RTOG (Radiation Therapy Oncology Group) protocols in which BCNU or PCV was used in conjunction with radiation therapy for anaplastic gliomas. For the entire cohort of patients included in these studies, there was no difference in disease-free or overall survival between the BCNU group (257 patients, $11 \%$ oligodendrogliomas) and the PCV group (175 patients, $23 \%$ oligodendrogliomas), despite the theoretical advantage of the increased fraction of oligodendroglial-based tumors in the PCV group. Moreover, a recently published paper by the Medical Research Council Brain Tumour Working Party reported no difference in overall survival for patients with high grade astrocytomas who either received radiotherapy alone (9.5 months) or radiotherapy followed by PCV therapy (10 months), after diagnosis. ${ }^{28}$ This study was randomized in design and involved a total of 674 patients.

\section{Platinum salts}

Platinum salts are broad-spectrum alkylating agents composed of a central platinum atom attached to two ammonia groups and one or more leaving groups, which confer its properties to the molecule. ${ }^{29-31}$ The most widely used agents in this category are cisplatin and carboplatin. These molecules both share the same spectrum of action (with only minor differences) but differ in their pharmacologic properties and toxicity. Carboplatin has a longer half-life ( 2.5 vs. 1 hours), less proteinbinding (24\% vs. $90 \%$ ), is more stable in physiological medium and is less neurotoxic than cisplatin. ${ }^{10,30,31}$ Main side effects for carboplatin consist in myelosupression and moderate nausea and vomiting. Toxicity for cisplatin consists of nephrotoxicity (reduced by adequate hydration of the patient), peripheral neuropathy, ototoxicity and severe nausea and vomiting, with less myelosupression than carboplatin. ${ }^{29-31}$

Platinum derivatives have mainly been tested in a rescue setting for malignant astrocytomas, when progression occurs after standard treatment. ${ }^{32-35}$ Most investigators have administered carboplatin, but trials of cisplatin have generated similar results. ${ }^{36}$ Yung et $\mathrm{al}^{35}$ treated 30 malignant astrocytoma patients with a monthly $400 \mathrm{mg} / \mathrm{m}^{2}$ intra-venous (i.v.) carboplatin dose. Overall response rate was $48 \%$ (14\% partial response and 34\% stable disease) with a MTP and MST of 26 and 50 weeks, respectively, for the responders. For the entire group, MTP was 11 weeks and MST, 29 weeks. Toxicity was low and generally well tolerated. Another phase II trial by Prados et al, ${ }^{32}$ with a similar dose-schedule, produced a partial response rate of $9.5 \%$ and a stabilization rate of $41.3 \%$, with a MTP of 12.5 weeks and a MST of 34.1 weeks for the whole group. The 63 patients treated in this study presented with malignant gliomas and had previously been exposed to cytotoxic agents. These results are similar to those achieved with nitrosoureas.

Few investigators have studied platinum salts in an adjuvant setting. One such study was published in 1996 by Lunardi et al. ${ }^{37}$ These investigators compared carboplatin to BCNU following resection and irradiation of malignant gliomas. Twenty patients in each group were given either carboplatin (from 450 to 600 $\mathrm{mg} / \mathrm{m}^{2}$ i.v.) for three cycles or one to two doses of BCNU. No significant difference was observed between the two groups, with median survival times ranging from 10.5 to 11 months. Neoadjuvant administration of ACNU and cisplatin was assayed by Choi et al. ${ }^{38}$ Two cycles of ACNU and cisplatin (each at 40 $\mathrm{mg} / \mathrm{m}^{2} /$ day in a continuous $72 \mathrm{~h}$ i.v. infusion) over six weeks were followed by standard radiotherapy. MTP and MST were 5.9 and 14.9 months, respectively.

Newer platinum derivatives with activity against tumors traditionally resistant to this class of agents are becoming available. Oxaliplatin is one such agent. Trials of oxaliplatin against colorectal tumors have generated enthusiastic results, and many phase II trials are presently underway to assess the effect of this compound against malignant astrocytomas.

\section{Temozolomide}

Temozolomide (TMZ), an imidazotetrazine derivative, is one of the newer alkylating agents. One of its major advantages over other agents is its complete bioavailability after oral intake. 5,39,40 It is related to dacarbazine, with which it shares its active moiety (monomethyl triazenoimidazole carboxamide or MTIC). However, unlike dacarbazine, which is a prodrug requiring liver activation, TMZ is spontaneously degraded into MTIC in the bloodstream at physiological $\mathrm{pH}^{5,36,37}$ Moreover, it has a good blood-brain barrier penetration when compared to other agents (25\% CSF:serum ratio). Main toxicity consists in thrombocytopenia, but nausea, fatigue, constipation and headache can also be encountered. Originally approved for use in patients with recurrent anaplastic astrocytomas, it has also recently been approved by the Food and Drug Administration for the treatment of newly diagnosed glioblastoma multiforme, administered concurrently with radiation therapy. The only other FDAapproved agents for malignant astrocytomas are the nitrosoureas. The standard TMZ regimen consists of a daily dose of 200 $\mathrm{mg} / \mathrm{m}^{2}$ for 5 consecutive days, repeated every 28 days. ${ }^{(5,39-42)}$ For the treatment of GBM, the treatment protocol consists in a daily dose of $75 \mathrm{mg} / \mathrm{m}^{2}$ during the six weeks of radiation therapy, followed by the 5 -day regimen over the following months. ${ }^{16}$

Temozolomide has initially been studied at tumor recurrence. Bower et $\mathrm{al}^{43}$ treated 103 patients (73 GBM, 20 AA, 10 various high grade gliomas), 31 of whom had previously received chemotherapy. Response and stabilization rate were $11 \%$ and 
47\% respectively, with a MTP of 4.2 months, and a MST of 5.8 months. One hundred and eleven anaplastic astrocytoma or mixed glioma patients were treated by Yung et al. in a similar setting. ${ }^{44}$ A complete response was observed in $8 \%$ of patients, partial response in $27 \%$ and stable disease in $27 \%$, for an overall response rate of $62 \%$. The MTP was 5.4 months and MST 13.6 months.

Temozolomide was compared to procarbazine (PCB) in major randomized studies. Yung et al. ${ }^{15}$ randomized 225 recurrent GBM patients into two groups. More than two thirds of the patients had previously been exposed to cytotoxic agents in both groups. Response and stabilization rates were $5.4 \%$ and $40.2 \%$, and $5.3 \%$ and $27.4 \%$ for the TMZ and PCB groups, respectively. Overall survival rates were not statistically different between the groups, but there was a clear advantage in favor of TMZ in regard to the progression-free survival (PFS). Median PFS was 12.4 vs. 8.3 weeks, and the six-months PFS was $21 \%$ compared to $8 \%$ in favor of TMZ. Severe toxicity from the treatment was observed in $25 \%$ of the PCB patients, compared to $18 \%$ in the TMZ group. Osoba et al. followed this study with an analysis of 363 recurrent GBM patients, 113 of whom were given $\mathrm{PCB}$ and 250, TMZ. ${ }^{14}$ The health-related quality of life (HRQL) data during the treatment was evaluated. For patients in the TMZ arm, progression-free survival was associated with an increase in the quality of life that was maintained until progression occurred. In contrast, there was a decrease in quality of life for the PCBtreated patients, even in the event of treatment response. This was mostly due to the side effects and toxicity of the drug. Similar results were obtained in recurrent AA patients, confirming the benefits in HRQL associated with TMZ treatment. $^{45}$

Other schedules of administration were investigated. ${ }^{46-49}$ One such protocol, devised by Stupp et al, ${ }^{49}$ showed promising preliminary results. Sixty-four newly-diagnosed GBM patients were given $75 \mathrm{mg} / \mathrm{m}^{2} /$ day for six weeks, concomitant with radiation therapy, after which standard TMZ monotherapy regimen $\left(200 \mathrm{mg} / \mathrm{m}^{2} /\right.$ day $)$ was continued for up to six cycles. The protocol was well tolerated and resulted in median survival time of 16 months, with 1- and 2-year survival rates of 58\% and $31 \%$, respectively.

These results led to the design of a major phase III study in which newly diagnosed GBM patients were randomized to either proceed with radiation therapy alone, or radiation combined with TMZ using the previously mentioned dose regimen. ${ }^{16}$ A total of 573 patients were enrolled in the study, 286 in the radiation-only group and 287 in the TMZ group. Both groups were well matched. Median survival time was 14.6 months against 12.1 months in favor of patients receiving TMZ. Two-year survival increased from $10.4 \%$ to $26.5 \%$ when on TMZ chemotherapy. The median progression-free survival was 6.9 months in the TMZ and 5 months in the radiation-only group. The 6 and 12month progression-free survival rate were $53.9 \%$ and $26.9 \%$ in the TMZ group, compared to $36.4 \%$ and $9.1 \%$ in the radiationonly group. At two years, $10.7 \%$ of patients still had not shown any disease progression, compared to $1.5 \%$ only in the radiation group. Grade 3 or 4 hematologic toxicity was seen in $7 \%$ of the TMZ-treated patients. It was after publication of this study that the FDA approval was received in this indication. In a smaller scale phase III study, Athanassiou et $\mathrm{al}^{50}$ randomized 130 patients to either radiation alone or chemo-radiation. While the TMZ dosage was the same as Stupp et $\mathrm{al}^{49}$ during radiation, patients on chemotherapy then received $150 \mathrm{mg} / \mathrm{m}^{2}$ for 5 days every 14 days. The MST were 13.4 and 7.7 months, in favor of the TMZ-treated patients, and the regimen was well tolerated. In view of all these results, concurrent TMZ and radiation therapy is now considered by many investigators to be the standard primary therapy for patients with a newly diagnosed glioblastoma multiforme.

\section{Etoposide and topo-isomerase II inhibitors}

Etoposide, an epipodophyllotoxin derivative, is the prototype and most commonly used topo-isomerase II inhibitor. Topoisomerases are enzymes involved in creating temporary breaks in DNA strands to allow unfolding and uncoiling during the process of replication. In the presence of etoposide, the enzyme cannot detach itself from the DNA strand, which leads to replication of defective DNA and eventually, apoptosis..$^{51-53}$ It is therefore Sphase specific, and activity is dependent on the exposition time, DNA possessing the capability to repair itself when exposition to etoposide subsides. The main toxicity of etoposide consists in myelotoxicity, particularly neutropenia. ${ }^{51-54}$ It is usually administered intravenously, because of its low oral bioavailability ( $40 \%$ to $75 \%$, depending on the dose) ${ }^{51-53}$ It poorly enters the central nervous system (CNS), displaying a maximal BBB penetration of less than $5 \% .{ }^{55}$ Nevertheless, because of its very broad spectrum and high efficiency in vitro against malignant astrocytomas, ${ }^{56}$ it has been widely used in clinical trials of recurrent disease. Typically, it has been combined with platinum salts because of its demonstrated synergistic effect with these agents. ${ }^{36,53}$

Impressive results with that combination were reported by Jeremic et $\mathrm{al}^{57}$ in 1992. This group treated 38 patients with recurrent tumors ( $30 \mathrm{GBM}$ and $8 \mathrm{AA}$ ), all previously exposed to chemotherapy. Their regimen consisted in three consecutive days of carboplatin ( $300 \mathrm{mg} / \mathrm{m}^{2}$ on day 1 to 3 ) simultaneous with 5 days of etoposide (100 mg/m 2 on day 1 to 5$)$, repeated every 28 days. A partial response rate of $21 \%$ and stable disease in $32 \%$ of the patients was observed. For the responders, MTP and MST were 42.5 and 47.5 weeks respectively, while corresponding data for the entire group was 14 and 43.5 weeks respectively. However, these results were attained at the expense of very high hematological and gastro-intestinal toxicities. A more recent study, by Franceschi et al ${ }^{58}$ reported a MTP and MST of 4 and 10 months, respectively, using $120 \mathrm{mg} / \mathrm{m}^{2}$ of etoposide and 100 $\mathrm{mg} / \mathrm{m}^{2}$ of carboplatin each day for three days, repeated every four weeks. The study group was comprised of $25 \mathrm{GBM}$ and 5 AA patients.

It is now well accepted that a prolonged schedule of administration for etoposide gives better response rates than standard schedule. ${ }^{52,53,59}$ Investigators have tried many regimens of oral etoposide in recurrent glioma patients. ${ }^{60-62}$ From in vitro studies, it has been established that a dose of $50 \mathrm{mg} / \mathrm{m}^{2}$ is the lowest dose that will achieve an effective central nervous system concentration..$^{59}$ Fulton et al ${ }^{60}$ administered a daily oral dose of $50 \mathrm{mg}$ of etoposide continuously to 46 recurrent malignant gliomas patients (36 malignant astrocytomas). Response rates of $8 \%$ and stabilization rates of $24 \%$ were obtained, with a MTP of 8.8 and MST of 24.5 weeks. 
Teniposide, a newer derivative, has also been tested in comparable settings, with results that were similar. ${ }^{60}$

\section{Topo-isomerase I inhibitors}

Drugs that can inhibit topo-isomerase I have been developed based on an extract from the tree Camptotheca acuminata. Mechanism of action and toxicity are similar to topo-isomerase II inhibitors. Irinotecan and topotecan are the two drugs in this class that are currently available for clinical use. Both were tested in the setting of recurrent glioma patients. In 1999, Friedman et $\mathrm{al}^{63}$ treated 60 patients (48 GBM, 10 AA and 2 mixed tumors) with a weekly dose of $125 \mathrm{mg} / \mathrm{m}^{2}$ of i.v. irinotecan for four consecutive weeks. Cycles were repeated every six weeks. In $15 \%$ of the patient population, partial responses (PR) was attained, and $55 \%$ of patients stabilized their disease. The MTP was 12 weeks and MST, 43 weeks, with 33\% still alive after one year. Almost no significant toxicity was observed. Macdonald et $\mathrm{al}^{64}$ tested a high-dose regimen of topotecan $\left(1.5 \mathrm{mg} / \mathrm{m}^{2}\right.$ daily for 3 weeks $)$ on 31 malignant glioma patients, with $6 \%$ of patients responding and $68 \%$ stabilizing. The MTP was 19 weeks. The price to pay for these results was an unacceptably high toxicity, however, with $58 \%$ grade IV neutropenia and $10 \%$ grade IV thrombocytopenia. Brandes et $\mathrm{al}^{65}$ used a combined regimen of BCNU and irinotecan on recurrent GBM patients who had already received temozolomide, based on preclinical studies showing synergistic activity. Forty-two patients received the combination therapy, and 9 attained a PR, while 21 more had stabilization of their disease. The MTP was 17 weeks and the MST, 11.7 months. The toxicity of the regimen was moderate.

A recent study reported the use of topotecan concomitantly to radiation therapy in newly diagnosed GBM patients. ${ }^{66}$ Sixty patients received a total of $60 \mathrm{~Gy}$ in 30 fractions of standard radiotherapy. Topotecan was administered as an absolute i.v. dose of $0.5 \mathrm{mg}$ one hour prior to irradiation, and the drug was discontinued at the end of the radiation regimen. The treatment was well tolerated. The overall survival time was 15 months, and one and two-year survival rates were $74 \%$ and $30 \%$, respectively.

\section{Taxanes derivatives}

Paclitaxel and docetaxel are cytotoxic agents that cause microtubule polymerisation, thereby blocking the cell cycle transition from G2 to the M phase. ${ }^{67-69}$ These drugs are usually administered i.v., and main toxicity consists in myelosupression, mucositis, myopathy and peripheral neuropathy. ${ }^{67-69}$ Dosage needs adjusting when patients also use anti-epileptic drugs, because these can lower serum taxane concentration by hepatic induction. ${ }^{70}$

Due to their effectiveness in gynecologic malignancy, much interest has been generated by these molecules for the treatment of recurrent malignant astrocytomas. Despite promising preclinical data showing activity against high-grade astrocytomas, ${ }^{71}$ a majority of investigators have concluded that these drugs are ineffective in that setting, after numerous negative clinical trials. ${ }^{70,72-75}$ The poor penetration across the BBB displayed by this class of agents might partially explain this fact. ${ }^{76}$ Chamberlain et al $^{72}$ treated 20 patients with an i.v. dose of paclitaxel, $175 \mathrm{mg} / \mathrm{m}^{2}$, every three weeks. Four patients responded and seven stabilized, for a MTP of six months. However, other investigators could not reproduce these results. More recently, Chang et al ${ }^{70}$ used dose-adjusted paclitaxel (330 or $210 \mathrm{mg} / \mathrm{m}^{2}$, depending on the usage of anticonvulsant drugs) to treat 19 patients. No patient responded and four attained stable disease status, for a MTP of one month only, and a MST of seven months. Pipas et $\mathrm{al}^{77}$ experienced using a combination of paclitaxel and topotecan on recurrent malignant astrocytomas. A partial response was obtained in $12 \%$ and stabilization in $41 \%$. However, $25 \%$ of patients suffered grade III or IV toxicity, with two patients dying of infectious complications.

Taxane analogs have recently been demonstrated to possess radio-sensitizing properties in vitro. ${ }^{78,79}$ If those results could be reproduced in in vivo studies, the drugs could then offer promises for use in an adjuvant or neoadjuvant setting.

\section{Anthracyclines}

Anthracyclines, first isolated from fermentation products of Streptomyces peucetus, were originally developed to be used as antibacterial agents. ${ }^{80,81}$ These molecules exert their cytotoxic effect through different mechanisms. ${ }^{80,81}$ Intercalation between DNA bases and inhibition of topo-isomerase II are the main action of these drugs. However, they also produce inhibition of helicase, an enzyme which splits double-stranded DNA into single strands. Finally, these agents are anthraquinones, which confers them the capability of generating free radicals. This last property is responsible for the main toxicity of the anthracyclines, cumulative non reversible cardiotoxicity, which leads to chronic heart failure after prolonged courses of treatment. ${ }^{80}$ Other important side effects include myelosupression and mucositis. These agents are usually administered intravenously, and poorly penetrate the blood-brain barrier. ${ }^{80}$

Few human clinical studies have been published using anthracyclines against malignant astrocytomas, due to their poor penetration of the cerebral parenchyma. However, these molecules have generated significant interest following the publication of many preclinical studies reporting major cytotoxic effect on glioma cell lines in vitro. ${ }^{82-86}$ Moreover, a recent metaanalysis comparing the chemosensitivity of multiple cell lines to different chemotherapeutic agents demonstrated a 500-fold greater potency for doxorubicin compared to nitrosoureas against malignant glioma cell lines. ${ }^{86}$

Newer derivatives with a higher lipophilicity were recently developed, with hopes of circumventing the blood-brain barrier. MX2, which is derived from daunorubicin, is one such compound. In animal studies, it demonstrated significantly less cardiotoxicity than other anthracyclines. ${ }^{87}$ This agent was used in clinical setting on patients at recurrence. Clarke et al, ${ }^{88}$ using a dosage of $40 \mathrm{mg} / \mathrm{m}^{2}$ i.v. every 28 days, treated 49 patients with malignant gliomas (including $31 \mathrm{GBM}$ and $15 \mathrm{AA}$ ). Ten of these patients had been previously exposed to chemotherapy. The results were as follow: $3 \mathrm{CR}, 1 \mathrm{PR}, 17 \mathrm{SD}$ (including 7 minor responses), for a MTP and MST of 2 and 11 months, respectively. Toxicity included neutropenia in 64\% (with 33\% grade IV), nausea in $51 \%$ and thrombocytopenia in $17 \%$. Another phase II trial, by Kuratsu et $a l,{ }^{89}$ treating 44 patients comprising a mixed population of recurrent gliomas with $35 \mathrm{mg} / \mathrm{m}^{2}$ i.v. every 21 or 28 days, produced one CR (AA) and 3 PR (2 AA, one brain stem glioma). Leucopenia in $72 \%$ and 
nausea in $31 \%$ were the main side effects. Kuratsu et al ${ }^{90}$ also investigated the use of the latter dosage regimen in a neoadjuvant setting. Thirteen patients were treated (5 GBM, 7 AA, 1 oligodendroglioma), 10 of which could be evaluated for response. Complete response was observed in 3 patients (including $1 \mathrm{GBM}$ and $2 \mathrm{AA}$ ), and stable disease in 3 patients (one of each histological subtype).

Liposomal encapsulation of anthracyclines is a way to improve their CNS penetration. Liposomal doxorubicin (Caelyx) has been used in patients with recurrent malignant astrocytomas (7 GBM, 1 gliosarcoma and 5 AA). ${ }^{91}$ Doses varied from 20 to 40 $\mathrm{mg} / \mathrm{m}^{2}$ i.v. every 2 weeks. A MTP of 11 weeks and MST of 40 weeks was attained. Chua et $\mathrm{al}^{92}$ recently reported the effects of the combination of TMZ and Caelyx in 22 recurrent GBM patients. The MTP and MST obtained were 3.2 and 8.2 months, respectively, with 1 patient attaining a CR, 3 PR and 11 SD.

\section{Chemoresistance}

Malignant cells can express resistance to the effect of cytotoxic therapy. Multiple mechanisms are implicated, but two are particularly well characterized in malignant astrocytomas: the enzyme O6-alkylguanine-DNA-alkyltransferase (AGT) and the multidrug resistance (MDR) gene product.

\section{O6-alkylguanine-DNA-alkyltransferase}

AGT is an enzyme that mediates resistance to alkylating agents. It is expressed by the majority of malignant astrocytomas, therefore limiting the efficacy of these compounds. As previously stated, the alkylating agents add alkyl groups to DNA nucleotides at diverse locus, most notably the O6 position of guanine. AGT works by extruding these alkyl groups from DNA. ${ }^{39,40}$ The enzyme becomes temporarily depleted after exposition to alkylating agents. ${ }^{40,93}$ This concept could find an application in combination regimens involving the sequential use of two alkylating agents.

The AGT gene expression depends on its promoter. Methylation of the promoter inactivates it, which results in the suppression of AGT activity in the cell. Different investigator groups have recently studied the methylation status of the AGT promoter in malignant astrocytomas patients, and correlated it with the response to alkylating agents, including temozolomide. ${ }^{94-96}$ Taken together, these results demonstrated that methylation of the promoter is an independent prognostic factor associated with a significant increase in the response rate to chemotherapy, as well as prolonged disease-free and overall survival.

O6-benzylguanine is a compound that has been developed as a false substrate to AGT, to prevent it from interfering with the activity of chemotherapy. In vitro studies in conjunction with temozolomide have demonstrated a significant increase in cytotoxicity against malignant astrocytoma cell lines. ${ }^{48}$ Recently, a phase I study by Friedman et $\mathrm{al}^{97}$ was conducted on 11 patients who were undergoing resection of malignant glioma. The patients were administered O6-benzylguanine 18 hours before surgery in doses ranging from 40 to $120 \mathrm{mg} / \mathrm{m}^{2}$ i.v.. The AGT activity was measured in the surgical specimens immediately upon their reception. At administered doses of $100 \mathrm{mg} / \mathrm{m}^{2}$ or higher, AGT was almost undetectable. No side effects were noted in any of the patients.

\section{Multidrug resistance gene}

The MDR gene encodes a protein, p-glycoprotein, which acts as a transmembrane efflux pump on the cytosolic membrane. ${ }^{53}$ It can extrude many cytotoxic agents from the interior of the tumor cell. Etoposide is one of the major drugs affected by this mechanism. ${ }^{51,53}$ Some drugs are know to inhibit this pump, among which are calcium blockers, cyclosporine and colchicine. ${ }^{53}$ Tamoxifen has generated promises in the treatment of malignant astrocytomas, one of the reasons being its ability to inhibit p-glycoprotein. ${ }^{98}$ It is one of the bases of its potential inclusion in combination regimen. It will be further discussed in the following sections.

\section{Biological Modifiers}

Biological modifiers are molecules acting on the intrinsic machinery that is mandatory for all basic cellular functions, including metabolism, proliferation, reproduction and migration. These agents have cytostatic properties and do not directly kill the neoplastic cells, but rather inactivate them. Many drugs are currently in development or in clinical trial phase and will be further discussed in the following sections.

\section{Differentiation agents}

Progressive change from a well differentiated phenotype to anaplasia represents one of the hallmarks of malignancy. In theory, differentiation agents have the property of reversing this dedifferentiation, inducing the phenotype of the neoplastic cell to revert back to normal. The main agents in this class include vitamin $\mathrm{A}$ and vitamin $\mathrm{D}$ derivatives.

Vitamin A derivatives, also known as retinoids, are mainly used for the treatment of severe acne vulgaris; however, they have been administered in oncology to patients with acute promyelocytic leukemia. ${ }^{99}$ These molecules exert their antineoplastic action via interaction with a nuclear receptor, analogous to steroid receptors. Mechanisms of action include inhibition of cellular proliferation, differentiation effect, inhibition of the expression of oncogenes (including EGFR) and increased cellular immunity. ${ }^{99-101}$ These drugs, which are liposolubles, can adequately penetrate the BBB and have been demonstrated to inhibit proliferation of GBM cells in vitro. ${ }^{101-103}$ Two different isomers are available for clinical use, transretinoic acid and cis-retinoid acid, which differ in their half-life and metabolism but have similar efficiency. ${ }^{104}$ Toxicity consists of dermatologic effects (mainly dryness and scaling of skin and mucous membranes) and mild to moderate headache. ${ }^{101}$

A few clinical studies using these agents on patients with malignant astrocytomas have been published. These trials principally involved patients with recurrent disease. Phuphanich et $\mathrm{al}^{105}$ treated 30 patients (including $14 \mathrm{GBM}$ and $14 \mathrm{AA}$ ) with $120 \mathrm{mg} / \mathrm{m}^{2} /$ day of all-trans-retinoic acid. Twelve percent of patients presented a PR and another $12 \%$ a SD, with a mean time to progression and survival time of 3.8 and 5.7 months, respectively. Another study, by Yung et al, ${ }^{106}$ enrolled 50 patients, among which $15 \mathrm{GBM}$ and $15 \mathrm{AA}$. Dosages of 60 to $100 \mathrm{mg} / \mathrm{m}^{2} /$ day of 13 -cis-retinoic acid, for a period of three weeks every month, were used. Response and stabilisation rates of $23 \%$ and $30 \%$, respectively, were attained with a MTP and MST of 16 and 52 weeks, respectively, for the entire cohort. In 
Table 1: Summary of relevant clinical standard chemotherapy studies

\begin{tabular}{ll}
\multicolumn{1}{c}{ Authors } & Patients, Sett \\
$\begin{array}{l}\text { Nitrosoureas } \\
\text { Brandes et al. (24) }\end{array}$ & $\begin{array}{l}40 \text { pts } \\
\text { Recurrent GBM }\end{array}$ \\
$\begin{array}{l}\text { Medical Research } \\
\text { Concil Brain Tumor }\end{array}$ & $\begin{array}{l}\text { Newly-diagnosed } \\
\text { high grade } \\
\text { Working Party (28) } \\
\text { astrocytomas }\end{array}$
\end{tabular}

\section{Platinum salts}

Yung et al. (35)

$\begin{array}{cl}\text { Yung et al. (35) } & \begin{array}{l}40 \text { pts, } \\ \text { Recurrent malignant } \\ \text { astrocytomas }\end{array} \\ \text { Prados et al. (32) } & \begin{array}{l}63 \text { pts, } \\ \text { Recurrent malignant } \\ \text { gliomas (31 GBM) }\end{array} \\ \begin{array}{ll}\text { Temozolomide } \\ \text { Bower et al. (43) }\end{array} & \begin{array}{l}103 \text { pts, } \\ \text { Recurrent } \\ \text { GBM (73) }\end{array} \\ & \begin{array}{l}\text { AA (20) } \\ \text { Other (10) } \\ 111 \text { pts, }\end{array} \\ & \begin{array}{l}\text { Recurrent AA or } \\ \text { anaplastic } \\ \text { oligoastrocytomas } \\ \text { Yung et al. (44) }\end{array} \\ & \begin{array}{l}\text { Newly-diagnosed } \\ \text { GBM }\end{array} \\ \text { Stupp et al. (16) } & \end{array}$

$\begin{array}{ll}\begin{array}{l}\text { Topo-isomerase } \\ \text { Fulton et al. (60) }\end{array} & \begin{array}{l}46 \text { pts, } \\ \text { Recurrent malignant }\end{array} \\ & \text { gliomas } \\ \text { Jeremic et al. (57) } & \begin{array}{l}38 \text { pts, } \\ \text { Recurrent GBM (30) } \\ \text { or AA (8) }\end{array} \\ & \\ \text { Friedman et al. } & \begin{array}{l}60 \text { pts, } \\ \text { (63) }\end{array} \\ & \begin{array}{l}\text { Recurrent malignant } \\ \text { astrocytomas }\end{array}\end{array}$

\section{Taxanes}

Chamberlain et al.

Chang et al. (70)

\section{Anthracyclines}

Clarke et al. (88)

Fabel et al. (91)

\section{0 pts,}

Recurrent malignant gliomas

23 pts,

Recurrent malignant astrocytomas

\section{9 pts,}

Recurrent malignant gliomas (31 GBM, 15 AA)

13 pts,

Recurrent malignant astrocytomas
Agents

BCNU $80 \mathrm{mg} / \mathrm{m}^{2} \times 3$
days every 8 weeks
RT alone vs. RT
followed by:
Procarbazine 100
$\mathrm{mg} / \mathrm{m}^{2}$ days 1 to 10
CCNU $100 \mathrm{mg} / \mathrm{m}^{2}$ day 1
Vincristine $1.5 \mathrm{mg} / \mathrm{m}^{2}$
(max $2 \mathrm{mg}$ )day 1

Carboplatin 400

$\mathrm{mg} / \mathrm{m}^{2}$ every month

Carboplatin 400

$\mathrm{mg} / \mathrm{m}^{2}$ every 3 weeks

TMZ $200 \mathrm{mg} / \mathrm{m}^{2} \times 5$

days, every 28 days

TMZ $200 \mathrm{mg} / \mathrm{m}^{2} \times 5$ days, every 28 days

Concomitant RT and TMZ $75 \mathrm{mg} / \mathrm{m}^{2} /$ day for 6 weeks, followed by TMZ $200 \mathrm{mg} / \mathrm{m}^{2} \times 5$ days, every 28 days (up to 6 cycles) vs. RT alone

Etoposide $50 \mathrm{mg} / \mathrm{m}^{2}$ orally every day

Every 28 days:

Etoposide $100 \mathrm{mg} / \mathrm{m}^{2}$ on day 1 to 5 Carboplatin $300 \mathrm{mg} / \mathrm{m}^{2}$ on day 1 to 3

Irinotecan $125 \mathrm{mg} / \mathrm{m}^{2}$ once per week $\times 4$ repeated every 6 weeks

\section{Paclitaxel 175 mg/m²} every 3 weeks

Paclitaxel 210 (if on anticonvulsants) or 330 $\mathrm{mg} / \mathrm{m}^{2}$ (no

anticonvulsant) every 3 weeks

MX2 $40 \mathrm{mg} / \mathrm{m}^{2}$ every

28 days

20 to $40 \mathrm{mg} / \mathrm{m}^{2}$ every 2 weeks
$43 \%$

response or stable

\section{Tumor response}

$\begin{array}{ll}\text { PR: } 15 \% & \text { MTP } 13.3 \text { weeks } \\ \text { SD: } 22.5 \% & \text { MST } 7.5 \text { months } \\ \text { NA } & \text { MST } 10 \text { months } \\ & \text { (compared to } 9.5 \\ & \text { months for patients } \\ & \text { receiving only } \\ & \text { radiation) }\end{array}$

PR: $14 \% \quad$ MTP 11 weeks

SD: $34 \% \quad$ MST 29 weeks

$50.8 \% \quad$ MTP 12.5 weeks

response or MST 34.1 weeks

stable

Response: MTP 4.2 months $11 \%$ MST 5.8 months

SD: $47 \%$

CR: $8 \%$

PR: $27 \%$

SD: $27 \%$

NA

MTP 5.4 months MST 13.6 months

MTP 6.9 months MST 14.6 months PFS-6: 53.9\% PFS-12: $26.9 \%$ PFS-24: $10.7 \%$

Response

$8 \%$

SD: $24 \%$

PR: $21 \%$

SD: $32 \%$

PR: $15 \%$

SD: $55 \%$

MTP 12 weeks

MST 43 weeks

PR: $20 \%$ SD: $35 \%$

No response SD: $21 \%$

MTP 8.8 weeks MST 24.5 weeks

MTP 14 weeks MST 43.5 weeks

No response SD: $54 \%$
MTP 2 months MST 11 months

MTP 11 weeks MST 40 weeks

TMZ: temozolomide, RT: radiation therapy, MTP: median time to progression, MST: median survival time, PFS-6: six-month progression-free survival, PFS-12: 12-month progression-free survival, PFS-24: 24-month progression-free survival, CR: complete response, SD: stable disease, PR: partial response, NA; not available 
the responders, at the time of publication, the MTP was 66 weeks, and the MST had not been reached. These results prompted the authors to quote that "a combination regimen of cis-retinoic acid with other biological agents or cytotoxic agents should be considered a priority". Recently, different phase II studies combining temozolomide and 13-cis retinoic acid were performed. In one of these studies, 88 eligible patients with recurrent tumors were treated, including 40 with GBM and 28 AA. ${ }^{107}$ For the whole group, 6-months PFS was $43 \%$, median PFS, 19 weeks and overall survival, 47 weeks. For the GBM subgroup, the 6-months PFS, median PFS and overall survival were $32 \%, 16$ weeks and 35 weeks, respectively. No additive toxicity was observed between the two agents. Another group studied the same combination given concomitantly with radiation therapy in newly diagnosed GBM patients. ${ }^{108}$ Unfortunately, although the treatment was well tolerated, no advantage was found compared to chemo-radiation with TMZ alone, with an overall survival time of 57 weeks.

Vitamin D derivatives, like retinoids, also possess differentiation properties. ${ }^{109,110}$ In addition, these drugs are proapoptotic, probably via an interaction with the p21 and p53 pathways, and via an increase in intracellular ceramide concentration. ${ }^{110,111}$ Ceramides are fatty acids possessing apoptotic properties. The actions of ceramides have been demonstrated in vitro on malignant glial cell lines (rodent and human). ${ }^{112,113}$ Moreover, a synergistic effect can be induced by the combination of vitamin D and retinoids. ${ }^{109}$ One clinical trial with impressive results was published by Trouillas et al. ${ }^{110}$ Eleven patients with de novo malignant astrocytomas (10 GBM and 1 AA) were treated immediately following surgery with a regimen consisting of $0.04 \mu \mathrm{g}$ of alfacalcidol on a long-term daily basis combined with standard cytotoxic agents (teniposide and nitrosoureas for a maximum of one year). There was no grade 3 or 4 toxicity and the MST was 21 months for the entire group, with a 2-year survival rate of $40 \%$. At the time of publication, 3 long-term survivors were still alive, including 2 GBM and 1 AA with a follow-up time of 50, 64 and 86 months respectively.

\section{Matrix metalloproteinase inhibitors}

Matrix metalloproteinase (MMP) are specific proteolytic enzymes involved in various normal physiological processes. Their functions include, among others, normal tissue remodeling, organogenesis during embryology, and wound healing. In addition, they are implicated in normal and pathologic inflammatory reactions, and tumorigenesis. ${ }^{114-118}$ In oncology, these enzymes are essential to the processes of basal membrane invasion, angiogenesis and metastasis, and are secreted directly by tumor cells or by the peritumoral stroma, under the influence of the tumor. ${ }^{114-118}$ At least 18 different MMPs have been characterized at the present time, among which collagenases (MMP-1, MMP-8 and MMP-13) and gelatinases (MMP-2, MMP-9) represents the main subtypes. ${ }^{114-118}$

Gelatinases are especially attractive as potential targets in oncology because they are key players in the process of tissular invasion via degradation of the basement membrane. The MMPs are expressed in malignant gliomas, and the degree of expression is directly correlated to the proliferative potential of the tumor. ${ }^{119-121}$
Type-specific and non specific inhibitors are being developed and tested in various clinical settings. ${ }^{114-116,118,122-125}$ Many authors reported interesting results on malignant gliomas in preclinical studies. SI-27, a specific inhibitor for MMP-2 and MMP-9 demonstrated a dose-dependant inhibition of invasion in many malignant glial cell lines, including U87-MG, U251-MG and U373-MG. ${ }^{126}$ AG3340, another selective gelatinase inhibitor, induced a significant increase in survival in a rodent intracranial glioma model. ${ }^{127}$

Marimastat, the most studied of these agents, is a non-specific inhibitor that can be administered orally with a low toxicity profile (mainly musculoskeletal). It was tested in phase III studies for the treatment of pancreatic (compared to gemcitabine), gastric (versus placebo) and small-cell pulmonary (versus placebo) malignancies without convincing results. ${ }^{116,118,123,124}$ Against malignant glioma, in vitro studies showed some degree of inhibition of invasion. ${ }^{128}$ However, a much-anticipated phase III trial of marimastat against placebo in GBM patients failed to demonstrate any advantage for the drug in terms of time to progression and survival time. ${ }^{129}$

Nevertheless, MMP inhibitors still generate much interest, and it is hoped that combination therapy involving these agents might yield better results. Groves et $\mathrm{al}^{130}$ administered TMZ combined with marimastat to 44 recurrent GBM patients. These authors observed 6 PR (13.6\%) and 26 SD (59\%). The MTP and MST were 17 and 45 weeks, respectively, and 12-month progression-free survival was $16 \%$. Musculoskeletal toxicity occurred in $47 \%$ of patients.

\section{Angiogenesis inhibitors}

Neoangiogenesis is characteristically an active process in malignant neoplasms and, as such, endothelial cells constitute an important part of the neoplastic bulk in high grade astrocytomas. This fact renders the endothelial cellular compartment an attractive target for antineoplastic treatment. Endothelial cells are a much more homogenous cellular population than malignant astrocytes, and are less subject to drug resistance. ${ }^{131}$ Moreover, these cells are easily reached by drugs in the systemic circulation. There are many known endogenous pro-angiogenic factors, some of which are specific for this purpose, such as vascular endothelium growth factor (VEGF) and angiopoietin. Non-specific factors include MMPs, which were discussed in the previous section, and integrins, membrane proteins primarily mediating cellular adhesion and migration. Overexpression of many of these factors has been demonstrated in many subsets of malignant astrocytomas. ${ }^{120,131-134}$

Endogenous inhibitors of angiogenesis have been characterized, and include platelet factor 4, thrombospondin, angiostatin and endostatin. ${ }^{131}$ Of those, angiostatin and endostatin have generated the most interest for use in anticancer strategies. Angiostatin is a $38 \mathrm{kDa}$ protein generated by the cleavage of a terminal fragment of plasminogen by elastase, and endostatin is a $22 \mathrm{kDa}$ fragment derived from collagen XVIII. ${ }^{131}$ Recombinant forms of these molecules have been synthesized and have shown promising results in preclinical trials, with apoptosis induction and inhibition of proliferation in vitro, ${ }^{135}$ and regression of intracranial and subcutaneous gliomas in a mouse model. ${ }^{136}$ Moreover, the combination of both molecules seems to be synergistic, ${ }^{137}$ as is their combination with ionizing radiation. ${ }^{138}$ Clinical studies are presently underway. 
Table 2: Summary of biological modifiers clinical studies

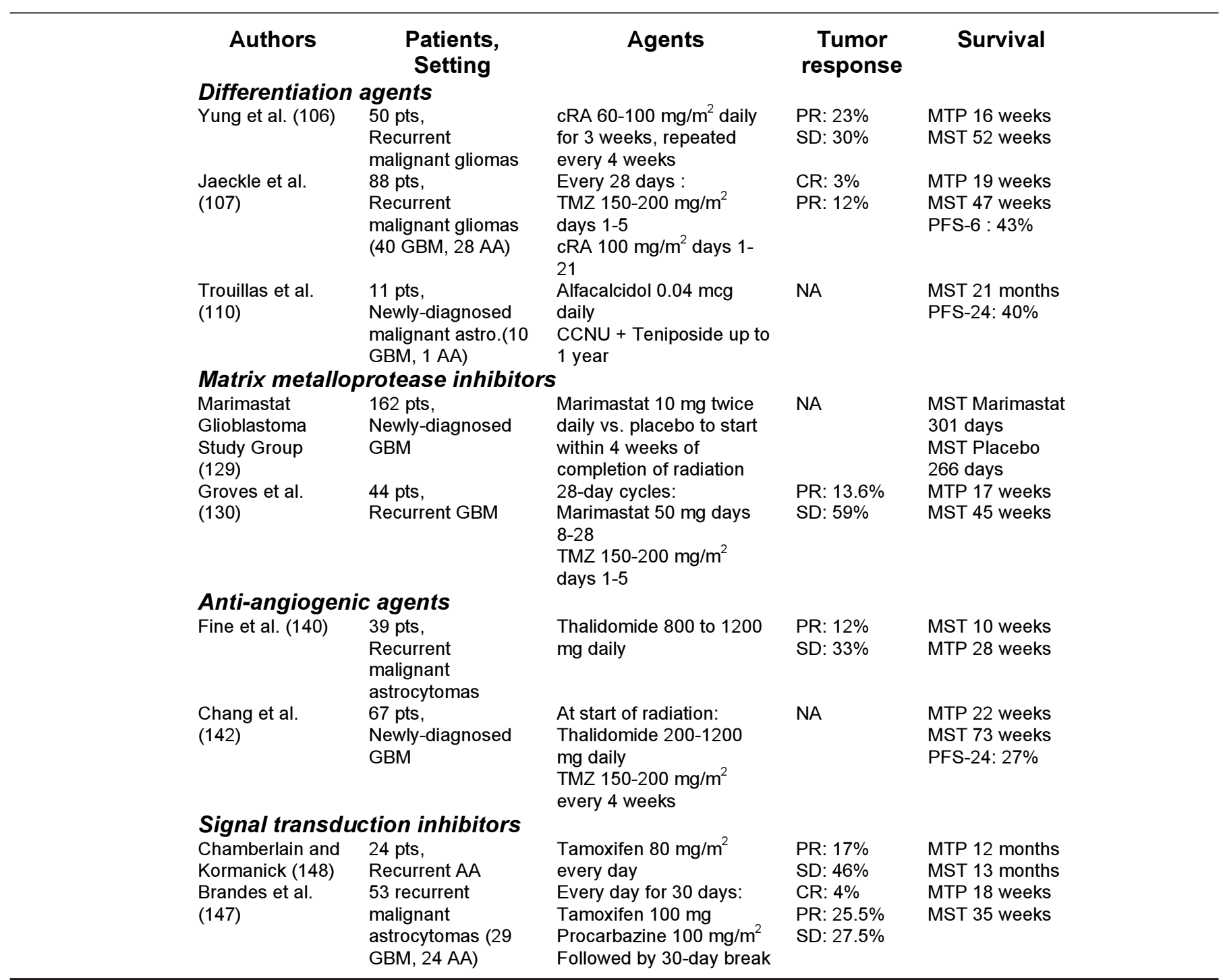

TMZ: temozolomide, cRA: 13-cis retinoic acid, MTP: median time to progression, MST: median survival time, PFS-6: six-month progression-free survival, PFS-24: 24-month progression-free survival, PR: partial response, SD: stable disease, CR: complete response, NA: not available

Thalidomide, a potent anti-emetic drug for pregnant women whose use was discontinued because of severe teratogenic effects, has demonstrated anti-angiogenic properties. ${ }^{131,139}$ Other potential anticancer effects of this agent include immunomodulation and interaction with adhesion molecules. ${ }^{139}$ Fine et $\mathrm{al}^{140}$ treated 39 patients with recurrent disease (25 GBM, 12 AA and 2 mixed gliomas) with 800 to $1200 \mathrm{mg}$ of thalidomide per day. Results obtained were as follows: 2 PR, 2 MR, 12 SD and 23 PD. The MTP and MST were 10 and 28 weeks, respectively, for the entire cohort, and 33 and 74 weeks, respectively, when analyzing only the subgroups of patients with a treatment response. Another group of investigators administered the drug to 18 high-grade glioma patients. ${ }^{141}$ Dosage was only $100 \mathrm{mg}$ per day on a continuous basis. All patients had received prior radiotherapy and chemotherapy, mostly nitrosourea-based. Only one patient responded and two stabilized (17\% PR+SD), and MST was 2.5 months. Both groups of authors concluded that although primary efficacy is low, this drug could find a use in the context of a multimodality treatment regimen.

Recently, papers reporting the use of TMZ combined with thalidomide in newly diagnosed GBM patients were published. Chang et $\mathrm{al}^{142}$ designed a protocol consisting of $150-200$ $\mathrm{mg} / \mathrm{m}^{2} /$ day for five consecutive days of TMZ every four weeks, and 200-1200 mg per day of thalidomide on a continuous basis. Temozolomide was started the same day as radiation therapy, while thalidomide was initiated on the seventh day, and both drugs were given as long as tolerated. The MST was 73 weeks, 
and 2-year survival, $27 \%$. The toxicity profile was similar to $\mathrm{TMZ}$ alone. Baumann et $\mathrm{al}^{143}$ compared thalidomide alone to a TMZ-thalidomide combination. These authors used the 5-day TMZ regimen, and thalidomide was limited to $600 \mathrm{mg}$ per day. However, the drugs were only started two weeks after the end of radiation therapy. Forty-four patients were treated. In the thalidomide group, MTP and MST were 17 and 63 weeks, respectively, compared to 36 and 103 weeks for the same parameters in the combination regimen group.

\section{Signal transduction inhibitors}

Malignant processes, like invasion and metastasis, necessitates the transduction of various signals derived from the interaction of the neoplastic cell with its surrounding. Receptors on the cellular membrane act via a variety of second messengers and intermediates to exert their effect on the cell. There are many potential targets for antineoplastic strategies along the pathways of signal transduction, among which are protein kinase $\mathrm{C}$ and $\mathrm{p} 21-\mathrm{Ras}$.

Protein kinase $\mathrm{C}$ is implicated in the regulation of gene expression, cytoskeleton alteration and ionic channels modulation. ${ }^{144}$ There is evidence for increased expression of protein kinase $\mathrm{C}$ in various malignant neoplasms, including highgrade astrocytomas. ${ }^{145}$ Tamoxifen is a selective estrogen receptor modulator (SERM) used for the treatment of breast cancer. Other than its anti-estrogen properties, effects of tamoxifen include inactivation of protein kinase $\mathrm{C}$ and inhibition of $\mathrm{p}$ glycoprotein. ${ }^{98}$ Tamoxifen toxicity includes nausea, hot flashes and increased propensity to thrombo-embolism. In vitro studies on malignant astrocytoma cells demonstrated a dose-dependant inhibition of proliferation and a sensitizing effect to radiation. ${ }^{146}$ Various authors have tested this drug in a clinical setting for treatment of malignant astrocytic tumors. ${ }^{147-153}$ In these studies, drug dosage varied from $20 \mathrm{mg}$ twice a day to $240 \mathrm{mg} / \mathrm{m}^{2}$ daily. Chamberlain and Kormanick ${ }^{148}$ administered $80 \mathrm{mg} / \mathrm{m}^{2}$ daily on a continual basis to a cohort of 24 heavily-pretreated patients with recurrent AA. Four patients demonstrated a PR and 11 stabilized their disease. The MTP was 12 months and MST, 13 months, for the entire group. Brandes et $\mathrm{al}^{147}$ tested a combination regimen involving tamoxifen (100 mg daily) and procarbazine $\left(100 \mathrm{mg} / \mathrm{m}^{2}\right.$ daily) on 53 patients with recurrent disease (29 GBM and 24 AA). The drugs were administered for 30 consecutive days, followed by a 30 day-break, and the cycle was repeated afterward. All patients had previously received chemotherapy with nitrosoureas. The CR, PR and SD rates were respectively $4 \%, 25.5 \%$ and $27.5 \%$, for a MTP of 18 weeks and MST of 35 weeks. Tamoxifen has also been studied in an adjuvant setting. Mastronardi et $\mathrm{al}^{151}$ randomized patients into two groups. Forty patients (34 GBM and 6 AA) were given i.v. carboplatin alone, and 40 (32 GBM and 8 AA) received a combination of i.v. carboplatin and oral tamoxifen in escalating doses (40 to $120 \mathrm{mg}$ daily). The MST was 9 months in the carboplatin group and 13 months in the combination group, while 12 and 24-month survival rates were $30 \%$ and $0 \%$, versus $52 \%$ and $32 \%$, all results achieving statistical significance in favor of the combination group. It therefore appears that tamoxifen could be a useful drug for the treatment of malignant astrocytomas, as a single agent or in combination regimen. However, the optimal dosage remains to be determined.
Ras proteins are localized on the inner surface of the cell membrane, coupled with different receptors. These proteins act as second messengers in the transduction of cellular signals, and play a role in proliferation, migration and differentiation. Anchorage of the protein on the cell membrane necessitates prenylation, which consists of the addition of a lipid moiety to the protein by one of two different enzymes (farnesyltransferase or geranylgeranyltransferase). ${ }^{154,155}$ Surexpression of $\mathrm{p} 21$-Ras is a commonly occurring event in neoplasia (around 30\%), and is caused by either a direct mutation in the protein or, more commonly, by dysregulation of upstream signaling. ${ }^{154,155}$ Prenylation enzyme inhibitors have been developed and tested in vitro on malignant glioma cell lines. ${ }^{154}$ These agents demonstrated dose and time-dependent inhibition of proliferation, in addition to a pro-apoptotic effect. An in vivo study using subcutaneous and intracranial grafts of the U87-MG line in athymic mice confirmed those results, with complete regression of subcutaneous tumors and prolonged survival for mice bearing intracranial neoplasm. ${ }^{156}$ Human trials are underway.

\section{Summary AND Conclusions}

Upon reviewing all the data pertaining to standard chemotherapy agents in the treatment of malignant astrocytomas, one can only recognize that so much effort has generated only modest results. The agents and protocols devised more than 30 years ago, consisting mostly in different combinations involving nitrosoureas, are still the ones used regularly in our era. The only major breakthrough was the recent recognition that temozolomide can lead to a statistically significant prolongation of overall survival and increased 2-year survival rate for glioblastoma multiforme patients, with maintenance of satisfying health-related quality of life, when administered concomitantly to fractionated radiation therapy after primary diagnosis. This is now leading to a change in the standard management of GBM, with incorporation of temozolomide in treatment protocols in most neuro-oncology centers. However, in spite of this progress, a cure for malignant astrocytic tumors remains far out of reach.

The lack of strong clinical evidence calls for a better design of clinical trials. In the past, numerous investigators have pooled patients with tumors of various histologies in the design of clinical trials. The analysis of the results in these studies is likely to include important biases caused by the heterogeneity of the tumor population. Valid conclusions cannot be drawn from such studies. The inclusion of mixed tumors and oligodendroglial tumors in trials involving astrocytic lesions should definitely be avoided. Even among astrocytic neoplasms, the different tumor grades (GBM vs. AA) should be analyzed separately, as the time course of the disease and the response to treatment is highly dissimilar. The RTOG recursive partitioning analysis criteria could be used in the design of inclusion criteria to improve comparison between treated groups, and between different studies. ${ }^{157}$ A major breakthrough in recent years is the recognition that molecular biology might play a role in the identification of prognostic criteria. This fact has been exemplified in oligodendrogliomas by the retrospective identification of $1 p$ and $19 q$ loss of heterozygosity as prognostic factors to chemotherapy response. ${ }^{26,158}$ Eventually, similar 
molecular markers might become available for malignant astrocytic tumors. Recently, silencing of the MGMT (O6methylguanine-DNA methyltransferase) DNA repair gene by promoter methylation was identified as an independent favorable prognostic factor in a population of 206 patients, $45 \%$ of which were positive for the methylation. ${ }^{159}$ The patients presenting with the methylated MGMT promoter also depicted greater benefit from chemotherapy than those who did not. Finally, future trials should also routinely incorporate HRQL analysis since it is probably the most important end-point for patients.

\section{AKNOWLEDGEMENT}

The authors thank Marie-Eve Potvin for editorial support with the manuscript.

\section{REFERENCES}

1. Kleihues P, Burger PC, Scheithauer BW. Histological typing of tumors of the central nervous system. International Histological Classification of Tumours. Geneva, Switzerland, World Health Organization, 1995.

2. Daumas-Duport C, Varlet P, Tucker M-L, et al. Oligodendrogliomas: Part 1-Patterns of growth, histological diagnosis, clinical and imaging correlations: A study of 153 cases. J Neurooncol. 1997; 34:37-59.

3. Kleihues P, Soylemezoglu F, Schauble B, Scheithauer BW, Burger PC. Histopathology, classification, and grading of gliomas. Glia. 1995; 15:211-221.

4. Alvord EC. Is necrosis helpful in the grading of gliomas? Editorial opinion. Neuropathol Exp Neurol. 1992; 51:127-32.

5. Friedman HS, Kerby T, Calvert H. Temozolomide and treatment of malignant glioma. Clin Cancer Res. 2000; 6:2585-97.

6. Giles GG, Gonzales MF. Epidemiology of brain tumors and factor in prognosis. In: Kaye AH, Laws ER, editors. Brain tumours, an encyclopedic approach. London: Churchill Livingstone; 2001, p. 51-70.

7. Silbergeld DL, Chicoine MR. Isolation and characterization of human malignant glioma cells from histologically normal brain. J Neurosurg. 1997; 86:525-31.

8. Huncharek M, Muscat J. Treatment of recurrent high grade astrocytoma; results of a systematic review of 1,415 patients. Anticancer Res. 1998; 18:1303-12.

9. Huncharek M, Muscat J, Geschwing JF. Multi-drug versus single agent chemotherapy for high grade astrocytoma; results of a meta-analysis. Anticancer Res. 1998; 18:4693-8.

10. Buatti JM, Marcus RB, Mendenhall WM, Friedman WA, Boya FJ. Accelerated hyperfractionated radiotherapy for malignant gliomas. Int J Radiat Oncol Biol Phys. 1996; 34:785-92.

11. Shin KH, Muller PJ, Geggie PHS. Superfractionation radiation therapy in the treatment of malignant astrocytoma. Cancer. 1983; 52:2040-3.

12. Laperriere N, Zuraw L, Cairncross G. The Cancer Care Ontario Practice Guidelines Initiative Neuro-Oncology Disease Site Group: radiotherapy for newly diagnosed malignant glioma in adults: a systematic review. Radiother Oncol. 2002; 64:259-73.

13. Brandes AA, Pasetto LM, Monfardini S. New drugs in recurrent high grade gliomas. Anticancer Res. 2000; 20:1913-20.

14. Osoba D, Brada M, Yung WKA, Prados MD. Health-related quality of life in patients treated with temozolomide versus procarbazine for recurrent glioblastoma multiforme. J Clin Oncol. 2000; 18:1481-91.

15. Yung WKA, Albright RE, Olson J, et al. A phase II study of temozolomide vs. Procarbazine in patients with glioblastoma multiforme at first relapse. Br J Cancer. 2000; 83:588-93.

16. Stupp R, Mason W, van de Bent MJ, et al. Radiotherapy plus concomitant and adjuvant temozolomide for glioblastoma. N Engl J Med. 2005; 352:987-96.
17. Fortin D. Altering the properties of the blood-brain-barrier: disruption and permeabilization. In: Prokai L, Prokai-Tatrai K, editors. Peptide transport and delivery into the central nervous system. Basel: Birkhauser; 2003. p. 127-54.

18. Walker MD, Alexander E Jr, Hunt WE, et al. Evaluation of BCNU and/or radiotherapy in the treatment of anaplastic gliomas. A cooperative clinical trial. J Neurosurg. 1978; 49:333-43.

19. Walker MD, Green SB, Byar DP, et al. Randomized comparisons of radiotherapy and nitrosoureas for the treatment of malignant glioma after surgery. N Engl J Med. 1980; 303:1323-9.

20. Van den Bent MJ. Chemotherapy in adult malignant glioma. Front Radiat Ther Oncol. 1999; 33:174-91.

21. Fine HA, Dear KBG, Loeffler JS, Black PM, Canellos GP. Metaanalysis of radiation therapy with and without adjuvant chemotherapy for malignant gliomas in adults. Cancer. 1993; 71:2585-97.

22. Stewart LA. Chemotherapy in adult high-grade glioma: a systematic review and meta-analysis of individual patient data from 12 randomised trials. Lancet. 2002; 359:1011-8.

23. Levin VA. Chemotherapy for brain tumors of astrocytic and oligodendroglial lineage: the past decade and where we are healing. Neuro-Oncol. 1999; 1:69-80.

24. Brandes AA, Tosoni A, Amista P, et al. How effective is BCNU in recurrent glioblastoma in the modern era? A phase II trial. Neurology. 2004; 63:1281-4.

25. Levin VA, Silver P, Hannigan J, et al. Superiority of postradiotherapy adjuvant chemotherapy with $\mathrm{CCNU}$, procarbazine and vincristine (PCV) over BCNU for anaplastic gliomas: NCOG 6G61 final report. Int J Radiat Oncol Biol Phys. 1990; 18:321-4.

26. Fortin D, Cairncross JG, Hammond RR. Oligodendroglioma: an appraisal of recent data pertaining to diagnosis and treatment. Neurosurgery. 1999; 45:1279-91.

27. Prados MD, Scott C, Curran WJ, et al. Procarbazine, Lomustine and Vincristine (PCV) chemotherapy for anaplastic astrocytoma: a retrospective review of radiation therapy oncology group protocols comparing survival with carmustine or PCV adjuvant chemotherapy. J Clin Oncol. 1999; 17:3389-95.

28. Medical Research Council Brain Tumour Working Party. Randomized trial of procarbazine, lomustine, and vincristine in the adjuvant treatment of high-grade astrocytomas: a Medical Research Council Trial. J Clin Oncol. 2001; 19:509-18.

29. Go RS, Adjei AA. Review of the comparative pharmacology and clinical activity of cisplatin and carboplatin. J Clin Oncol. 1999; 17:409-22.

30. O'Duyer PJ, Stevenson JP, Johnson SW. Clinical pharmacokinetics and administration of established platinum drugs. Drugs. 2000; 59 S4:19-27.

31. Selvaratnam G, Philips RH, Mohamed AK, Radzi A. Adverse effects of cytotoxics-platinum agents. Adverse Drug React Toxicol Rev. 1997; 16:171-97.

32. Prados MD, Warnick RE, Mack EE, et al. Intravenous carboplatin for recurrent gliomas. Am J Clin Oncol. 1996; 19:609-12.

33. Twelves CJ, Ash CM, Miles DW, Thomas DGT, Souhami RL. Activity and toxicity of carboplatin and iproplatin in relapsed high-grade glioma. Cancer Chemother Pharmacol. 1991; 27:481-3.

34. Warnick RE, Prados MD, Mack EE, et al. A phase II study of intravenous carboplatin for the treatment of recurrent gliomas. J Neurooncol. 1994; 19:69-74.

35. Yung WKA, Mechitler L, Gleason MJ. Intravenous carboplatin for recurrent malignant glioma: A phase II study. J Clin Oncol. 1991; 9:860-4.

36. Huncharek M, Kupelnick B, Bishop D. Platinum analogues in the treatment of recurrent high grade astrocytoma. Cancer Treat Rev. 1998; 24:307-16.

37. Lunardi P, Farah JO, Mastronardi L, Puzzilli F, Lo Bianco FM. Intravenous administration of high doses of carboplatin in multimodal treatment of high grade gliomas: a phase II study. Acta Neurochir. 1996; 138:215-20.

38. Choi IS, Lee SH, Kim TY, et al. Phase II study of chemotherapy with ACNU plus cisplatin followed by cranial irradiation in patients with newly diagnosed glioblastoma multiforme. J Neurooncol. 2002; 60:171-6. 
39. Brandes AA, Pasetto LM, Vastola F, Monfardini S. Temozolomide in patients with high grade gliomas. Oncology. 2000; 59:181-6.

40. Newlands ES, Stevens FG, Wedge SR, Wheelhouse RT, Brock C. Temozolomide: a review of its discovery, chemical properties, pre-clinical development and clinical trials. Cancer Treat Rev. 1997; 23:35-61.

41. Friedman HS. Temozolomide in early stages of newly diagnosed malignant glioma and neoplastic meningitis. Semin Oncol. 2000; 27:35-40.

42. Yung WKA. Temozolomide in malignant gliomas. Sem Oncol. 2000; 27:27-34.

43. Bower M, Newlands ES, Bleehen NM, et al. Multicentre CRC phase II trial of temozolomide in recurrent or progressive high-grade glioma. Cancer Chemother Pharmacol. 1997; 40:484-8.

44. Yung WKA, Prados MD, Yaya-Tur R, et al. Multicenter phase II trial of temozolomide in patients with anaplastic astrocytoma or anaplastic oligoastrocytoma at first relapse. J Clin Oncol. 17:2762-71.

45. Osoba D, Brada M, Yung WKA, Prados MD. Health-related quality of life in patients with anaplastic astrocytoma during treatment with temozolomide. Eur J Cancer. 2000; 36:1788-95.

46. Brock CS, Newlands ES, Wedge SR, et al. Phase I trial of Temozolomide using an extended continuous oral schedule. Cancer Res. 1998; 58:4363-7.

47. Khan RB, Raizer JJ, Malkin MG, Bazylewicz KA, Abrey LE. A phase II study of extended low-dose temozolomide in recurrent malignant gliomas. Neuro-oncol. 2002; 4:39-43.

48. Prados MD. Future directions in the treatment of malignant gliomas with temozolomide. Sem Oncol. 2000; 27:41-6.

49. Stupp R, Dietrich P, Kraljevic SO, et al. Promising survival for patients with newly diagnosed glioblastoma multiforme treated with concomitant radiation plus temozolomide followed by adjuvant temozolomide. J Clin Oncol. 2002; 20:1375-82.

50. Athanassiou H, Synodinou M, Maragoudakis E, et al. Randomized phase II study of temozolomide and radiotherapy compared with radiotherapy alone in newly diagnosed glioblastoma multiforme. J Clin Oncol. 2005; 23:2372-7.

51. Hande KR. Etoposide pharmacology. Sem Oncol. 1992; 19 S13:3-9.

52. Hande KR. Etoposide: four decades of development of a topoisomerase II inhibitor. Eur J Cancer. 1998; 34:1514-21.

53. Simon J. The clinical pharmacology of etoposide: an update. Cancer Treat Rev. 1996; 22:179-221.

54. Kobayashi Ratain MJ. New perspectives on the toxicity of etoposide. Semin Oncol. 1992; 19 S13:78-83.

55. Kiya K, Uozumi T, Ogasawara H, et al. Penetration of etoposide into human malignant brain tumors after intravenous and oral administration. Cancer Chemother Pharmacol. 1992; 29:339-42.

56. Beauchesne P, Bonner JA, Mornex F, Brunon J. Étude de la sensibilité à l'étoposide de lignées humaines de gliomes malins. Mécanismes d'action. Cancer Radiother. 1999; 3:57-64.

57. Jeremic B, Grujicic D, Jevremovic S, et al. Carboplatin and etoposide chemotherapy regimen for recurrent malignant glioma: a phase II study. J Clin Oncol. 1992; 10:1074-7.

58. Franceschi E, Cavallo G, Scopece L, et al. Phase II trial of carboplatin and etoposide for patients with recurrent high-grade glioma. Br J Cancer. 2004; 91:1038-44.

59. Hainsworth JD. Extended-schedule oral etoposide in selected neoplasms and overview of administration and scheduling issues. Drugs. 1999; 58 Supp3:51-6.

60. Fulton D, Urtasun R, Forsyth P. Phase II study of prolonged oral therapy with etoposide (VP16) for patients with recurrent malignant glioma. J Neurooncol. 1996; 27:149-55.

61. Korones DN, Fisher PG, Cohen KJ, Dubowy RL. No responses to oral etoposide in 15 patients with recurrent brain tumors. Med Pediat Oncol. 2000; 35:80-2.

62. Needle MN, Molloy PT, Ceyer JR, et al. Phase II study of daily oral etoposide in children with recurrent brain tumors and other solid tumors. Med Pediat Oncol. 1997; 29:28-32.

63. Friedman HS, Petros WP, Friedman AH, et al. Irinotecan therapy in adults with recurrent or progressive malignant glioma. J Clin Oncol. 1999; 17:1516-25.
64. MacDonald D, Cairncross G, Stewart D, et al. Phase II study of topotecan in patients with recurrent malignant glioma. Ann Oncol. 1996; 7:205-7.

65. Brandes AA, Tosoni A, Basso U, et al. Second-line chemotherapy with irinotecan plus carmustine in glioblastoma recurrent or progressive after first-line temozolomide chemotherapy: a phase II study of the Gruppo Italiano Cooperativo di Neuro-Oncologia (GICNO). J Clin Oncol. 2004; 22:4779-86.

66. Gross MW, Altscher R, Brandtner M, et al. Open-label simultaneous radio-chemotherapy of glioblastoma multiforme with topotecan in adults. Clin Neurol Neurosurg. 2005; 107:207-13.

67. Long HJ. Paclitaxel (Taxol): a novel anticancer chemotherapeutic drug. Mayo Clin Proc. 1994; 69:341-5.

68. Rowinsky EK, Nave LA, Donehower RC. Taxol: a novel investigational antimicrotubule agent. J Natl Cancer Inst . 1990; $82: 1247-59$

69. Vaishampayan U, Parchment RE, Jasti BR, et al. Taxanes: an overview of the pharmacokinetics and pharmacodynamics. Urology. 1999; 54:S22-9.

70. Chang SM, Kuhn JG, Robins HI, et al. A phase II study of paclitaxel in patients with recurrent malignant glioma using different doses depending upon the concomitant use of anticonvulsants. Cancer. 2001; 91:417-22.

71. Terzis AJ, Thorsen F, Heese O, et al. Proliferation, migration and invasion of human glioma cells exposed to paclitaxel (Taxol) in vitro. Br J Cancer. 1997; 75:1744-52.

72. Chamberlain MC, Kormanik PA. Salvage chemotherapy with paclitaxel for recurrent primary brain tumors. J Clin Oncol. 1995; 13:2066-71.

73. Forsyth P, Cairncross G, Stewart D, et al. Phase II trial of docetaxel in patients with recurrent malignant glioma: a study of the National Cancer Institute of Canada Clinical Trials Group. Invest New Drugs. 1996; 14:203-6.

74. Postma TJ, Heimans JJ, Luykx SA, et al. A phase II study of paclitaxel in chemonaive patients with recurrent high-grade glioma. Ann Oncol. 2000; 11:409-13.

75. Sanson M, Napolitano M, Yaya R, et al. Second line chemotherapy with docetaxel in patients with recurrent malignant glioma: a phase II study. J Neurooncol. 2000; 50:245-9.

76. Rowinsky EK. Taxane analogues: distinguishing royal robes from the "Emperor's new clothes". Clin Cancer Res. 2002; 8:2759-63.

77. Pipas JM, Meyer LP, Rhodes CH, et al. A phase II trial of paclitaxel and topotecan with filgrastim in patients with recurrent or refractory glioblastoma multiforme or anaplastic astrocytoma. J Neurooncol. 2005; 71:301-5.

78. Koukourakis MI, Giatromanolaki A, Schiza S, Kakolyris S, Georgoulias V. Concurrent twice-a-week docetaxel and radiotherapy: a dose escalation trial with immunological toxicity evaluation. Int J Radiat Oncol Biol Phys. 1999; 43:107-14.

79. Wehbe T, Glantz M, Choy $\mathrm{H}$, et al. Histologic evidence of a radiosensitizing effect of Taxol in patients with astrocytomas. J Neurooncol. 1998; 39:245-51.

80. Hande KR. Clinical applications of anticancer drugs targeted to topoisomerase II. Biochim Biophys Acta. 1998; 1400:173-84.

81. Lown JW. Anthracycline and anthraquinone anticancer agents: current status and recent developments. Pharmac Ther. 1993; 60:185-214.

82. Darling JL, Thomas DG. Response of short-term cultures derived from human malignant glioma to aziridinylbenzoquinone, etoposide and doxorubicin: an in vitro phase II trial. Anticancer Drugs. 2001; 12:753-60.

83. Kaaijk P, Troost D, de Boer OJ, et al. Daunorubicin and doxorubicin but not BCNU have deleterious effects on organotypic multicellular spheroids of gliomas. Brit J Cancer. 1996; 74:187-93.

84. Kuratsu J, Mihara Y, Kochi M, Takaki S, Ushio Y. Antitumor effect of a new anthracyclines derivative, MX2, against human glioma cells. Gan To Kagaku Ryoho. 1989; 16:399-403.

85. Stan AC, Casares S, Radu D, Walter GF, Brumeanu TD. Doxorubicin-induced cell death in highly invasive human gliomas. Anticancer Res. 1999; 19:941-50.

86. Wolff JEA, Trilling T, Mölenkamp G, Egeler RM, Jürgens H. Chemosensitivity of glioma cells in vitro: a meta-analysis. J Cancer Res Clin Oncol. 1999; 125:481-6. 
87. Sato Y, Eddy L, Hochstein P. Comparative cardiotoxicity of doxorubicin and a morpholino anthracycline derivative (KRN8602). Biochem Pharmacol. 1991; 42:2283-7.

88. Clarke K, Basser RL, Underhill C, et al. KRN8602 (MX2Hydrochloride): an active new agent for the treatment of recurrent high-grade glioma. J Clin Oncol. 1999; 17:2579-84.

89. Kuratsu J, Arita N, Kurisu K, et al. A phase II study of KRN8602 (MX2), a novel morpholino anthracyclines derivative, in patients with recurrent malignant glioma. J Neurooncol. 1999; 42:177-81.

90. Kuratsu J, Arita N, Kayama T, et al. Phase II trial of pre-irradiation KRN8602 (MX2) in malignant glioma patients. J Neurooncol. 2000; 48:145-9.

91. Fabel K, Dietrich J, Hau P, et al. Long-term stabilization in patients with malignant glioma after treatment with liposomal doxorubicin. Cancer 2001; 92:1936-42.

92. Chua SL, Rosenthal MA, Wong SS, et al. Phase II study of temozolomide and Caelyx in patients with recurrent glioblastoma multiforme. Neuro-oncol. 2004; 6:38-43.

93. Plowman J, Waud WR, Koutsoukos AD, et al. Preclinical antitumor activity of Temozolomide in mice: efficacy against human brain tumor Xenografts and Synergism with 1,3-Bis (2-chloroethyl)-1nitrosourea. Cancer Res. 1994; 54:3793-9.

94. Esteller M, Garcia-Foncillas J, Andion E, et al. Inactivation of the DNA-repair gene MGMT and the clinical response of gliomas to alkylating agents. N Engl J Med. 2000; 343:1350-4.

95. Hegi ME, Diserens AC, Godard S, et al. Clinical trial substantiates the predictive value of O-6_Methylguanine-DNA Methyltransferase promoter methylation in glioblastoma patients treated with temozolomide. Clin Cancer Res. 2004; 10:1871-4.

96. Hegi ME, Diserens AC, Gorlia T, et al. MGMT gene silencing and benefit from temozolomide in glioblastoma. N Engl J Med. 2005; 352:997-1003.

97. Friedman HS, Kokkinakis DM, Pluda J, et al. Phase I trial of O6Benzylguanine for patients undergoing surgery for malignant glioma. J Clin Oncol. 1998; 16:3570-5.

98. Mastronardi L, Puzzilli F, Ruggeri A. Tamoxifen as a potential treatment of glioma. Anticancer Drugs. 1998; 9:581-6.

99. Tallman MS, Wiernik PH. Retinoids in cancer treatment. J Clin Pharmacol. 1992; 32:868-88.

100. Pemrick SM, Lucas DA, Grippo J. The retinoid receptors. Leukemia. 1994; 8:1797-1806.

101. Westarp ME, Westarp MP, Grundl W, Biesalski H, Kornhuber HH. Improving medical approaches to primary CNS malignancies Retinoid therapy and more. Med Hypotheses. 1993; 41:267-76.

102. Bouterfa H, Picht T, Keb D, et al. Retinoids inhibit human glioma cell proliferation and migration in primary cell cultures but not in established cell lines. Neurosurgery. 2000; 46:419-30.

103. Mukherjee P, Das SK. Action of retinoic acid on human glioblastoma-astrocytoma - 14 cells in culture. Neoplasma. 1995; 42:123-8.

104. Muindi JRF, Young CW, Warrell Jr RP. Clinical pharmacology of all-trans retinoic acid. Leukemia. 1994; 8:1807-12.

105. Phuphanich S, Scott C, Fischbach AJ, Langer C, Yung WKA. Alltrans-retinoic acid: a phase II radiation therapy oncology group study (RTOG 91-13) in patients with recurrent malignant astrocytoma. J Neurooncol. 1997; 34:193-200.

106. Yung WKA, Kyritsis AP, Gleason MJ, Levin VA. Treatment of recurrent malignant gliomas with high-dose 13-cis-retinoic acid. Clin Cancer Res. 1996; 2:1931-5.

107. Jaeckle KA, Hess KR, Yung WKA, et al. Phase II evaluation of temozolomide and 13-cis retinoic acid for the treatment of recurrent and progressive malignant glioma: a North American Brain Tumor Consortium study. J Clin Oncol. 2003; 21:2305-11.

108. Butowski N, Prados MD, Lamborn KR, et al. A phase II study of concurrent temozolomide and cis-retinoic acid with radiation for adult patients with newly diagnosed supratentorial glioblastoma. Int J Radiat Oncol Biol Phys. 2005; 61:1454-9.

109. Magrassi L, Butti G, Pezzotta S, Infuso L, Milanesis G. Effects of vitamin $\mathrm{D}$ and retinoic acid on human glioblastoma cell lines. Acta Neurochir. 1995; 133:184-90.
110. Trouillas P, Honnorat J, Bret P, Jouvert A, Gerard JP. Redifferentiation therapy in brain tumors: long-lasting complete regression of gliobastomas and an anaplastic astrocytoma under long term 1-alpha-hydroxycholecalciferol. J Neurooncol. 2001; 51:57-66.

111. Magrassi L, Adorni L, Montorfano G, et al. Vitamin D metabolites activate the sphingomyelin pathway and induce death of glioblastoma cells. Acta Neurochir. 1998; 140:707-14.

112. Baudet C, Chevalier G, Naveilhan P, et al. Cytotoxic effects of 1 alpha, 25-dihydroxyvitamin D3 and synthetic vitamin D3 analogues on a glioma cell line. Cancer Lett. 1996; 100:3-10.

113. Naveilhan P, Berger F, Haddad K, et al. Induction of glioma cell death by $1,25(\mathrm{OH}) 2$ vitamin $\mathrm{D} 3$ : towards an endocrine therapy of brain tumors? J Neurosci Res. 1994; 37:271-7.

114. Brown PD. Matrix metalloproteinase inhibitors in the treatment of cancer. Med Oncol. 1997; 14:1-10.

115. Brown PD. Matrix metalloproteinase inhibitors. Breast Cancer Res Treat. 1998; 52:125-36.

116. Hidalgo M, Eckhardt SG. Development of matrix metalloproteinase inhibitors in cancer therapy. J Natl Cancer Inst. 2001; 93:178-93.

117. Rémy L. Données récentes sur les métalloprotéinases, acteurs incontournables de la progression tumorale [in French]. Pathol Biol. 1997; 45:759-65.

118. Yip D, Ahmad A, Karapetis CS, Hawkins CA, Harper PG. Matrix metalloproteinase inhibitors: applications in oncology. Invest New Drugs. 1999; 17:387-99.

119. Chintala SK, Tonn JC, Rao JS. Matrix metalloproteinases and their biological function in human gliomas. Int J Dev Neurosci. 1999; 17:495-502.

120. Thier M, Roeb E, Breuer B, et al. Expression of matrix metalloproteinase-2 in glial and neuronal tumor cell lines: inverse correlation with proliferation rate. Cancer Lett. 2000; 149:63-70.

121. Uhm JH, Dooley NP, Villemure JG, Yong VW. Mechanisms of glioma invasion: role of Matrix-Metalloproteinases. Can J Neurol Sci. 1997; 24:3-15.

122. Brown PD. Matrix metalloproteinase inhibitors: a novel class of anticancer agents. Adv Enzyme Regul. 1995; 35:293-301.

123. Brown PD. Clinical studies with matrix metalloproteinase inhibitors. APMIS. 1999; 107:174-80.

124. Rothenberg ML, Nelson AR, Hande KR. New Drugs on the Horizon: Matrix Metalloproteinase Inhibitors. Stem Cells. 1999; 17:237-40.

125. Talbot DC, Brown PD. Experimental and clinical studies on the use of matrix metalloproteinase inhibitors for the treatment of cancer. Eur J Cancer. 1996; 32:2528-33.

126. Noha M, Yoshida D, Watanabe K, Teramoto A. Suppression of cell invasion on human malignant glioma cell lines by a novel matrixmetalloproteinase inhibitor SI-27: in vitro study. J Neurooncol. 2000; 48:217-23.

127. Price A, Shi Q, Morris D, et al. Marked inhibition of tumor growth in a malignant glioma tumour model by a novel synthetic matrix metalloproteinase inhibitor AG3340. Clin Cancer Res. 1999; 5:845-54.

128. Tonn JC, Kerkau S, Hanke A, et al. Effect of synthetic matrixmetalloproteinase inhibitors on invasive capacity and proliferation of human malignant gliomas in vitro. Int J Cancer. 1999; 80:764-72.

129. Brown PD. Ongoing trials with matrix metalloproteinase inhibitors. Exp Opin Invest Drugs. 2000; 9:2167-77.

130. Groves MD, Puduvalli VK, Hess KR, et al. Phase II trial of Temozolomide plus the Matrix Metalloproteinase Inhibitor, Marimastat, in recurrent and progressive Glioblastoma Multiforme. J Clin Oncol. 2002; 20:1383-8.

131. Kirsch M, Schackert G, Black PM. Anti-angiogenic treatment strategies for malignant brain tumors. J Neurooncol. 2000; 50:149-63.

132. Plate KH, Breier G, Weich HA, Risau W. Vascular endothelial growth factor is a potential tumour angiogenesis factor in human gliomas in vivo. Nature. 1992; 359:845-8.

133. Stratmann A, Risau W, Plate KH. Cell type-specific expression of angiopoietin-1 and angiopoietin-2 suggests a role in glioblastoma angiogenesis. Am J Pathol. 1998; 153:1459-66. 
134. Zagzag D, Hooper A, Friedlander DR, et al. In situ expression of angiopoietins in astrocytomas identifies angiopoietin-2 as an early marker of tumor angiogenesis. Exp Neurol. 1999; 159:391-400.

135. Dhanabal M, Ramchandran R, Waterman MJ, et al. Endostatin induces endothelial cell apoptosis. J Biol Chem. 1999; 274:11721-6.

136. Griscelli F, Li H, Bennaceur-Griscelli A, et al. Angiostatin gene transfer: inhibition of tumor growth in vivo by blockage of endothelial cell proliferation associated with a mitosis arrest. Proc Natl Acad Sci USA. 1998; 95:6367-72.

137. Yokoyama Y, Dhanabal M, Griffioen AW, Sukhatme VP, Ramakrishnan S. Synergy between angiostatin and endostatin: inhibition of ovarian cancer growth. Cancer Res. 2000; 60:2190-6.

138. Gorski DH, Mauceri HJ, Salloum RM, et al. Potentiation of the antitumor effect of ionizing radiation by brief concomitant exposures to angiostatin. Cancer Res. 1998; 58:5686-9.

139. Singhal S, Mehta J. Thalidomide in cancer. BioDrugs. 2001; 15:163-72.

140. Fine HA, Figg WD, Jaeckle K, et al. Phase II trial of the antiangiogenic agent thalidomide in patients with recurrent highgrade gliomas. J Clin Oncol. 2000; 18:708-15.

141. Short SC, Traish D, Dowe A, et al. Thalidomide as an anti-angiogenic agent in relapsed gliomas. J Neurooncol. 2001; 51:41-5.

142. Chang SM, Lamborn KR, Malec M, et al. Phase II study of temozolomide and thalidomide with radiation therapy for newly diagnosed glioblastoma multiforme. Int J Radiat Oncol Biol Phys. 2004; 60:353-7.

143. Baumann F, Bjeljac M, Kollias SS, et al. Combined thalidomide and temozolomide treatment in patients with glioblastoma multiforme. J Neurooncol. 2004; 67: 191-200.

144. Horgan K, Cooke E, Hallett MB, Mansel RE. Inhibition of protein kinase-C mediated signal transduction by tamoxifen. Biochem Pharmacol. 1986; 35:4463-5.

145. Nishizuka Y. Studies and perspectives of protein kinase-C. Science. 1986; 233:305-12.

146. Zhang W, Yamada H, Sakai N, Niikawa S, Nozawa Y. Enhancement of radiosensitivity by tamoxifen in C6 Glioma Cells. Neurosurgery. 1992; 31:725-30.

147. Brandes AA, Ermani M, Turazzi S, et al. Procarbazine and HighDose Tamoxifen as a second-line regimen in recurrent high-grade gliomas: a phase II study. J Clin Oncol. 1999; 17:645-50.
148. Chamberlain MC, Kormanik PA. Salvage Chemotherapy with tamoxifen for recurrent anaplastic astrocytomas. Arch Neurol. $1999 ; 56: 703-8$.

149. Chang SM, Baker II FG, Huhn SI, et al. High dose oral tamoxifen and subcutaneous interferon alpha-2a for recurrent glioma. J Neurooncol. 1998; 37:169-76.

150. Couldwell WT, Weiss MH, DeGiorgio CM, et al. Clinical and radiographic response in a minority of patients with recurrent malignant gliomas treated with high-dose tamoxifen. Neurosurgery. 1993; 32:485-90.

151. Mastronardi L, Puzzilli F, Couldwell WT, Osman FJ, Lunardi P. Tamoxifen and carboplatin combinational treatment of highgrade gliomas. J Neurooncol. 1998; 38:59-68.

152. Muanza T, Shenouda G, Souhami L, et al. High dose tamoxifen and radiotherapy in patients with glioblastoma multiforme: a phase IB study. Can J Neurol Sci. 2000; 27:302-6.

153. Vertosick FT, Selker RG, Pollack IF, Arena V. The treatment of intracranial malignant gliomas using orally administered tamoxifen therapy: preliminary results in a series of « failed » patients. Neurosurgery. 1992; 30:897-903.

154. Bredel M, Pollack IF, Freund JM, Hamilton AD, Sebti SM. Inhibition of Ras and related G-Proteins as a therapeutic strategy for blocking malignant glioma growth. Neurosurgery. 1998; 43:124-32.

155. Bredel M, Pollack IF. The $\mathrm{p} 21$-Ras signal transduction pathway and growth regulation in human high-grade gliomas. Brain Res Rev. 1999; 29:232-49.

156. Pollack IF, Bredel M, Erff M, Hamilton AD, Sebti SM. Inhibition of Ras and related guanosine triphosphate-dependent proteins as a therapeutic strategy for blocking malignant glioma growth: IIpreclinical studies in a nude mouse model. Neurosurgery 1999; 45:1208-15.

157. Curran WJ Jr, Scott CB, Horton J et al. Recursive partitioning analysis of prognostic factors in three Radiation Therapy Oncology Group malignant glioma trials. J Natl Cancer Inst. 1993; 85:704-10.

158. Cairncross JG, Ueki K, Zlatescu MC, et al. Specific genetic predictors of chemotherapeutic response and survival in patients with anaplastic oligodendrogliomas. J Natl Cancer Inst. 1998; 90:1473-9.

159. Hegi ME, Diserens AC, Gorlia T, et al. MGMT gene silencing and benefit from temozolomide in glioblastoma. N Engl J Med. 2005; 352:997-1003. 